\title{
KARAKTERISTIK DAN KELAYAKAN LAHAN BUDI DAYA TAMBAK DI KECAMATAN SAMPARA, KABUPATEN KENDARI, PROVINSI SULAWESI TENGGARA
}

\begin{abstract}
Akhmad Mustafa*), Tarunamulia*), dan Adi Hanafi“')
ABSTRAK

Tujuan studi ini adalah untuk karakteristik dan kelayakan lahan tambak di Kecamatan Sampara, Kabupaten Kendari, Provinsi Sulawesi Tenggara. Karakteristik lahan yang diamati meliputi kualitas tanah dan air serta vegetasi dominan. Peubah yang digunakan adalah peubah kualitas tanah yang merupakan peubah penting untuk tanah sulfat masam dan melalui aplikasi Sistem Informasi Geografis (SIG) untuk menentukan kelayakan lahan untuk budi daya tambak. pesisir Kecamat, bahwa tanah sulfat masam merupakan jenis tanah yang mendominasi kawasan da kerada dalam kasan yang kualitas airnya mendukung budi daya tambak. Vegetasi dominan yang diidentifikasi sebagai Nypa fruticans dan Rhizophora sp. dan didapatkan pada tanah sulfat masam serta dapat digunakan sebagai indikator biologi untuk ditetapkan 483,77 aktual dan potensial. Dari 1.206,54 ha yang disurvai, di Kecamatan Sampara ditetapkan 483,77 ha termasuk kelayakan tinggi; 592,55 ha termasuk kelayakan sedang; dan 130,22 ha termasuk kelayakan rendah atau tidak layak untuk budi daya tambak.
\end{abstract}

ABSTRACT: Characteristics and land suitability for brackishwater pond in Sampara District, Kendari Regency, Southeast Sulawesi Province. By: Akhmad Mustafa,
Tarunamulia, and Adi Hanafi

The objectives of this study were to determine the potential for brackishwater pond development, and the characterization and land suitability for aquaculture at Sampara District and Kendari Regency, Southeast Sulawesi. Land characteristics examined consist of soil and water quality, and vegetation. Soil quality, related to acid sulfate soil, was used as a variable in the application of Geographic Information Systems (GIS) to land suitability assessment for brackishwater pond Good water. The results showed that most of the soils were associated with acid sulfate soil. vegetation vegetation species, such as Nypa fruticans and Rhizophora sp., were recorded on acid sulfate surveyed, around 483.77 hator for actual and potential soil acidification. From 1,206.54 ha of land and 130.22 has and 130.22 ha was low or not suitable for brackishwater ponds in Sampara District.

KEYWORDS: GIS, land suitability, brackishwater pond, Southeast Sulawesi

\section{PENDAHULUAN}

Rawa pasang surut di Indonesia diperkirakan seluas $6-8$ juta ha atau 3\%-4\% dari seluruh daratan Indonesia atau sekitar 7\%-10\% dari daratan pantai Indonesia (Notohadiprawiro, 1986). Sumber daya lahan ini dinilai potensial bagi pengembangan budi daya tambak, karena didukung oleh sumber daya air yang memadai.

Pemberdayaan dan pengembangan sumber daya lahan memerlukan pendalaman pengetahuan mengenai potensi melalui karakterisasi sumber daya lahan tersebut. Potensi sumber daya lahan di Kawasan Timur Indonesia khususnya untuk subsektor perikanan sebagian besar belum dimanfaatkan secara optimal, termasuk wilayah Provinsi Sulawesi Tenggara. Di tingkat nasional, pemerintah telah menetapkan pengembangan budi daya tambak melalui intensifikasi seluas 7.494 ha di Sulawesi Tenggara (Nurjana, 1999). Jenis tanah yang sering dijumpai di kawasan pesisir Indonesia termasuk Provinsi Sulawesi Tenggara adalah tanah sulfat masam dan tanah gambut. Keberadaan tanah marginal tersebut di kawasan pesisir yang lingkungan perairannya mendukung untuk usaha budi daya tambak, berdampak pada banyaknya tanah tersebut yang digunakan untuk usaha budi daya tambak. Namun demikian, dalam pemanfaatannya dijumpai berbagai kendala yang pada akhirnya menyebabkan rendahnya produktivitas tambak.

\footnotetext{
Peneliti pada Balai Riset Perikanan Budidaya Air Payau, Maros

Peneliti pada Balai Besar Riset Perikanan Budidaya Laut, Gondol
} 
Untuk mengantisipasi kerusakan dan menjaga kelestarian sumber daya lahan, maka pemberdayaan dan pengembangan sumber daya lahan harus dikelola dan direncanakan sebaik mungkin. Pengembangan budi daya tambak yang tidak sesuai dengan daya dukung lahan berdampak pada rendahnya produktivitas tambak dan tidak berlanjut, seperti kasus yang dijumpai di Kecamatan Pangkajene, Kabupaten Pangkep (Mustafa \& Hanafi, 1996). Evaluasi kemampuan lahan merupakan proses untuk menduga kelayakan sumber daya lahan bagi berbagai penggunaan termasuk untuk usaha budi daya tambak. Sebagai langkah awal dalam pemberdayaan dan pengembangan sumber daya lahan, sangat diperlukan informasi mengenai kelayakan lahan tersebut. Berbagai metode telah banyak dikemukakan dan digunakan untuk evaluasi sumber daya lahan, namun dalam pemberdayaan dan pengembangannya tidak terlalu tepat karena hanya menggunakan peubah tertentu secara parsial dan tidak terpadu dan menyeluruh.

Sebagai alternatif yang tepat dari permasalahan tersebut adalah dengan menggunakan teknologi Sistem Informasi Geografis (SIG). Dengan teknologi ini akan dapat dilakukan evaluasi yang terpadu dan menyeluruh yang dapat digunakan untuk pemberdayaan dan pengembangan potensi lahan (Purwadhi, 1999). Oleh karena itu, SIG akan sangat bermanfaat dalam pemberdayaan dan pengembangan sumber daya lahan budi daya tambak. Informasi hasil evaluasi lahan dalam bentuk kelayakan lahan budi daya tambak dapat digunakan sebagai dasar dalam menentukan pengembangan wilayah, termasuk untuk penyusunan rencana tata ruang wilayah Provinsi Sulawesi Tenggara secara umum dan Kabupaten Kendari secara khusus. Untuk itu dilakukan survai yang bertujuan mengetahui karakteristik dan kelayakan lahan tambak di Kecamatan Sampara, Kabupaten Kendari, Provinsi Sulawesi Tenggara.

\section{BAHAN DAN METODE}

Kegiatan diawali berupa diskusi dengan key informan seperti: Kepala dan Staf Dinas Perikanan dan Kelautan Provinsi Sulawesi Tenggara, Dinas Perikanan dan Kelautan Kabupaten Kendari, serta Staf Balai Pengkajian Teknologi Pertanian Kendari untuk menentukan lokasi survai. Survai dilaksanakan di kawasan pesisir Kecamatan Sampara, Kabupaten Kendari, Provinsi Sulawesi Tenggara pada Iahan seluas $1.206,54$ ha.

Survai didahului dengan melihat garnbaran lokasi survai secara umum dan dilanjutkan dengan penentuan titik-titik pengambilan contoh tanah dan air serta pengamatan vegetasi. Penentuan titik pengambilan contoh tanah didasarkan pada perbedaan penggunaan tanah yaitu: pemukiman, tambak, kebun campuran, kebun kelapa, dan hutan mangrove. Pengambilan contoh tanah dilakukan secara acak pada penggunaan tanah yang sama.

Pengambilan contoh tanah dilakukan dengan menggunakan bor tanah pada kedalaman 0--20, 2040, dan 40-60 cm lokasi tambak dan hutan mangrove, serta dilanjutkan pada kedalaman 60-80, 80100, dan 100-120 cm pada tanah pematang tambak, kebun campuran, dan kebun kelapa. Peubah kualitas tanah yang diukur langsung di lapangan meliputi: $\mathrm{pH}_{\mathrm{F}}$ dengan $\mathrm{pH}$-meter, $\mathrm{pH}_{\mathrm{Fox}}$ dengan $\mathrm{pH}$-meter, reaksi peroksida dengan hidrogen peroksida, dan tekstur dengan metode rasa. Pengambilan contoh air dilakukan di pantai (Laut Banda), Sungai Sampara, Pulu, Lalimbuejaya, Mutui, dan Labota, serta dalam tambak. Seluruh contoh tanah dan air disimpan dalam cold box yang telah diberi es, masing-masing mengikuti petunjuk Ahern \& Blunden (1998) dan APHA (1998).

Contoh tanah dikeringkan dalam oven pada suhu $80^{\circ} \mathrm{C}-85^{\circ} \mathrm{C}$ selama minimal 48 jam mengikuti petunjuk Ahern \& Blunden (1998). Selanjutnya dilakukan analisis kualitas tanah berupa peubah bahan organik, total actual acidity (TAA), total potential acidity (TPA), total sulfidic acidity (TSA), dan $\mathrm{S}_{\text {TSA }}$ mengikuti petunjuk Ahern et al. (1998). Analisis kualitas air yang meliputi $\mathrm{pH}$, salinitas, padatan tersuspensi total TSS (total suspended solid), BOT, $\mathrm{NH}_{3}-\mathrm{N}, \mathrm{NO}_{3}-\mathrm{N}, \mathrm{NO}_{2}-\mathrm{N}$, dan $\mathrm{PO}_{4}-\mathrm{P}$, serta $\mathrm{SO}_{4}$-S dilakukan mengikuti petunjuk Menon (1973) dan APHA (1998).

Aplikasi Sistem Informasi Geografis (SIG) digunakan untuk pembuatan peta. Kriteria yang digunakan didasarkan pada kurva-kurva hipotesis dan studi korelasi berbagai peubah tanah dan air terhadap produktivitas tambak. Pengambilan dan penentuan titik-titik pengambilan contoh dilakukan berdasarkan kaidah-kaidah pemetaan termasuk kaidah penentuan posisi dengan Global Positioning System (GPS) dan interpolasi data bila diperlukan (Gambar 1). Analisis grafis secara individu dari setiap peubah tanah untuk selanjutnya dikombinasi dengan metode tumpang tindih untuk memperoleh peta kelayakan lahan budi daya tambak.

\section{HASIL DAN BAHASAN}

\section{Gambaran Umum Lokasi Survai}

Secara administrasi, lokasi survai terletak di Kecamatan Sampara, Kabupaten Kendari, Provinsi Sulawesi Tenggara. Lokasi survai dibatasi Sungai Mutui di sebelah utara; Sungai Labota di sebelah barat, Sungai Sampara di sebelah selatan, dan Laut Banda 


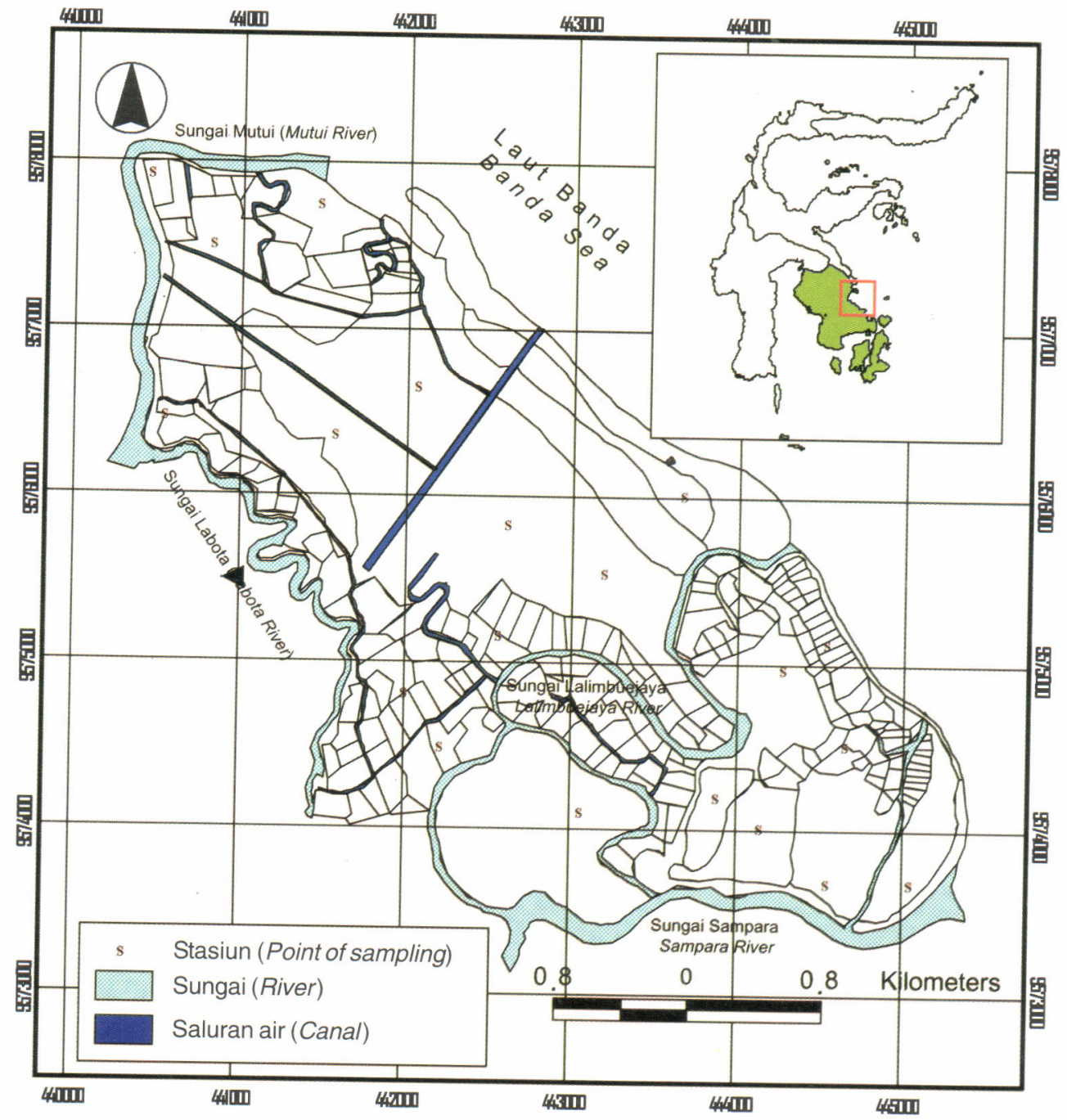

Gambar 1. Posisi titik-titik pengambilan contoh tanah di kawasan pesisir Kecamatan Sampara, Kabupaten Kendari, Provinsi Sulawesi Tenggara

Figure 1. Distribution of soil sampling points in coastal area of Sampara District, Kendari Regency, Southeast Sulawesi Province

di sebelah timur. Di bagian tengah lokasi survai mengalir pula Sungai Lalimbuejaya yang bermuara di Laut Banda dan Sungai Pulu yang bermuara di Sungai Sampara bagian muara.

Lokasi survai dapat dijangkau dengan kendaraan darat dari Kendari sampai ke Batugong yang berjarak 17 km (3 km jalan aspal dan 14 km jalan tanah). Lokasi survai juga dapat ditempuh dengan kendaraan air dari Laosu (5 km dari Kendari) sekitar 45 menit perjalanan (boat dengan mesin 15 PK).

Di lokasi survai dijumpai 5 jenis pemanfaatan lahan yaitu: pemukiman, tambak, kebun campuran, kebun kelapa, dan hutan mangrove. Lokasi tambak terletak di pinggir pantai antara Sungai Sampara dan Sungai Lalimbuejaya, di sebelah kiri dan kanan Sungai Pulu, Lalimbuejaya, Mutui, dan Labota. Mangrove yang tersisa dijumpai di sepanjang sungai yang ada, hutan mangrove yang relatif luas dijumpai di dekat Sungai Sampara. Kebun campuran dan kelapa terutama dijumpai di antara pinggir pantai (Sungai Lalimbuejaya dan Mutui) dan pemukiman.

Selain dijumpai sungai yang dapat menjadi sarana pengairan tambak, juga telah dibangun saluran primer sepanjang $1.500 \mathrm{~m}$ dengan lebar $24 \mathrm{~m}$ serta beberapa saluran primer dan tersier. Saluran tersebut tidak hanya melalui daerah tambak tetapi juga areal kebun campuran, sehingga akan memungkinkan konversi kebun campuran menjadi areal tambak.

Seperti halnya dengan daerah lain di Indonesia, di Kecamatan Sampara memiliki dua musim yaitu: musim hujan (November s.d. April) dan musim kemarau (Mei s.d.Oktober). Puncak musim hujan 
terjadi pada bulan Desember dan Januari. Suhu udara maksimal $34^{\circ} \mathrm{C}$ dan minimal $20^{\circ} \mathrm{C}$ dengan kelembaban udara rata-rata $84 \%$.

\section{Karakteristik Lahan}

\section{Kualitas tanah}

Secara umum dijumpai dua jenis tanah yaitu: tanah mineral (tanah sulfat masam) dan tanah organik (tanah gambut) di kawasan pesisir Kecamatan Sampara. Tanah sulfat masam dijumpai di kawasan pesisir yang tergolong intertidal maupun supratidal, sedangkan tanah gambut hanya dijumpai di kawasan pesisir yang tergolong intertidal. Tanah gambut dijumpai dalam kawasan intertidal yaitu dalam hutan mangrove atau dalam tambak yang baru dibuka yang merupakan konversi hutan mangrove. Di beberapa tempat di Kecamatan Sampara dijumpai pula tanah sulfat masam yang berasosiasi dengan tanah gambut.

Tanah gambut yang ditumbuhi vegetasi mangrove akan mudah berkembang menjadi tanah sulfat masam yang terbentuk di bawah tegakan Rhizophora sp. (Williams \& Joseph, 1976 dalam Mustafa et al., 1994). Hal ini disebabkan oleh terdapatnya bahan endapan dan sisa-sisa akar Rhizophora sp. yang berserat-serat. Rhizophora apiculata, R. mucronata, Bruguiera gymnorrhiza, dan Nypa fruticans banyak mengandung tanin yang dapat menurunkan $\mathrm{pH}$ tanah (Gonzales et

Tabel 1. Kualitas tanah di kawasan pesisir Kecamatan Sampara, Kabupaten Kendari, Provinsi Sulawesi Tenggara

Table 1. Soil quality in coastal area of Sampara District, Kendari Regency, Southeast Sulawesi Province

\begin{tabular}{|c|c|c|c|c|c|c|c|c|c|c|c|c|}
\hline \multicolumn{2}{|c|}{$\begin{array}{c}\text { Koordinat } \\
\text { Coordinat (UTM) }\end{array}$} & \multicolumn{11}{|c|}{ Peubah (Variables) } \\
\hline$x$ & $Y$ & $\mathrm{pH}_{\mathrm{F}}$ & $\mathrm{pH}_{\mathrm{FOx}}$ & $\begin{array}{l}\mathrm{RP} \\
P R\end{array}$ & $\begin{array}{c}\text { Bahan } \\
\text { organik } \\
\text { Organic } \\
\text { matter } \\
(\%)\end{array}$ & $\mathrm{pH}_{\mathrm{KCl}}$ & $\mathrm{pH}_{\mathrm{ox}}$ & $\begin{array}{l}\text { TPA } \\
(\mathrm{mol} \\
\mathrm{H}+/ \mathrm{t})\end{array}$ & $\begin{array}{l}\text { TAA } \\
(\mathrm{mol} \\
\mathrm{H}+/ \mathrm{t})\end{array}$ & $\begin{array}{l}\text { TSA } \\
(\mathrm{mol} \\
\mathrm{H}+\mathrm{t})\end{array}$ & $\mathrm{S}_{\mathrm{TSA}}(\%)$ & $\begin{array}{l}\text { Tekstur } \\
\text { Texture }\end{array}$ \\
\hline 443975 & 9575112 & 5.66 & 3.94 & 2 & 5.26 & 5.04 & 3.48 & 58.5 & 56.0 & 2.5 & 0.8098 & SC \\
\hline 443539 & 9573539 & 6.01 & 3.66 & 2 & 4.86 & 5.90 & 5.86 & 0 & 0 & 0 & 0 & SC \\
\hline 443215 & 9574323 & 6.45 & 1.03 & 2 & 5.00 & 5.78 & 2.28 & 220.5 & 0 & 220.5 & 0.3535 & $\mathrm{SdC}$ \\
\hline 442788 & 9574466 & 3.84 & 0.85 & 3 & 8.72 & 3.21 & 2.19 & 439.0 & 36.5 & 402.5 & 0.6543 & $\mathrm{SC}$ \\
\hline 442268 & 9573935 & 6.32 & 1.48 & 2 & 5.39 & 5.79 & 2.76 & 155.5 & 0 & 155.5 & 0.2493 & $\mathrm{SdC}$ \\
\hline 441856 & 9573533 & 6.36 & 3.07 & 2 & 3.83 & 5.93 & 5.98 & 0 & 0 & 0 & 0 & $\mathrm{C}$ \\
\hline 442276 & 9576918 & 5.11 & 4.33 & 2 & 2.05 & 5.74 & 3.65 & 29.0 & 0 & 29.0 & 0.0465 & Sd \\
\hline 442276 & 9576356 & 4.83 & 3.70 & 2 & 2.82 & 4.44 & 5.96 & 19.0 & 13.0 & 6.0 & 0 & $\mathrm{SdC}$ \\
\hline 441656 & 9575480 & 4.41 & 2.82 & 2 & 5.70 & 5.73 & 2.68 & 103.0 & 0 & 103.0 & 0.1651 & $\mathrm{SdC}$ \\
\hline 441592 & 9576893 & 5.69 & 0.90 & 3 & 19.19 & 5.72 & 1.98 & 604.5 & 0 & 604.5 & 0.9692 & SdCL \\
\hline 441683 & 9576637 & 5.73 & 2.20 & 2 & 7.69 & 5.44 & 2.23 & 291.0 & 0 & 291.0 & 0.4666 & $\mathrm{SdC}$ \\
\hline 440184 & 9576415 & 6.32 & 2.84 & 2 & 10.05 & 5.19 & 1.96 & 470.0 & 2.5 & 467.5 & 0.7496 & SdCL \\
\hline 440454 & 9576437 & 6.06 & 1.36 & 2 & 8.07 & 5.40 & 1.80 & 281.5 & 0 & 281.5 & 0.4513 & $3 \mathrm{SdL}$ \\
\hline 440763 & 9575689 & 6.07 & 4.36 & 1 & 2.04 & 5.88 & 2.48 & 112.0 & 0 & 112.0 & 0.1796 & $\mathrm{Sd}$ \\
\hline 440980 & 9575753 & 4.93 & 3.04 & 1 & 2.01 & 5.82 & 2.59 & 76.0 & 0 & 76.0 & 0.1219 & $\mathrm{Sd}$ \\
\hline 441496 & 9574797 & 5.67 & 4.22 & 1 & 4.57 & 5.36 & 2.71 & 94.0 & 0 & 94.0 & 0.1507 & $\mathrm{SdL}$ \\
\hline 441225 & 9573782 & 6.18 & 1.45 & 2 & 4.76 & 4.72 & 2.24 & 158.5 & 6.0 & 152.5 & 0.2245 & $5 \mathrm{SdC}$ \\
\hline 442072 & 9572714 & 6.46 & 2.61 & 1 & 1.57 & 5.42 & 3.49 & 74.0 & 0 & 74.0 & 0.1186 & SC \\
\hline 444968 & 9573761 & 5.96 & 1.66 & 2 & 4.89 & 5.27 & 2.73 & 204.0 & 0 & 204.0 & 0,3271 & SC \\
\hline 444762 & 9573632 & 5.95 & 1.85 & 2 & 6.81 & 4.45 & 2.07 & 298.0 & 2.5 & 295.5 & 0.4738 & SC \\
\hline 444462 & 9573656 & 2.66 & 1.28 & 2 & 4.69 & 3.05 & 3.08 & 92.0 & 37.5 & 54.5 & 0.0874 & SdL \\
\hline$R P$ & \multicolumn{5}{|c|}{ Reaksi peroksida (PR: peroxide reaction) } & 7) & & \multicolumn{5}{|c|}{ Liat (Clay) } \\
\hline TPA & \multicolumn{5}{|c|}{ Total potential acidity } & Sc & & \multicolumn{5}{|c|}{ Pasir (Sand) } \\
\hline TAA & \multicolumn{5}{|c|}{ Total actual acidity } & SC & & \multicolumn{5}{|c|}{ : Liat berdebu (Silty clay) } \\
\hline TSA & \multicolumn{5}{|c|}{ : Total sulfidic acidity } & & $\mathrm{dC}:$ & \multicolumn{5}{|c|}{ : Liat berpasir (Sandy clay) } \\
\hline $\begin{array}{l:}\mathrm{S}_{\mathrm{TSA}} \\
\mathrm{SdCL}\end{array}$ & \multicolumn{6}{|c|}{$\begin{array}{l}\text { : TSA calculated as equivalent pyrite S \% } \\
\text { : Lempung liat berpasir (Sandy clay loam) }\end{array}$} & $\mathrm{dL}:$ & \multicolumn{5}{|c|}{ : Lempung berpasir (Sandy loam) } \\
\hline
\end{tabular}


al., 1974). Keadaan inilah yang menyebabkan $\mathrm{pH}$ tanah sulfat masam dan tanah gambut tergolong rendah (Tabel 1) di kawasan pesisir Kecamatan Sampara terutama pada daerah tambak dan hutan mangrove. Selain itu, tanah sulfat masam di Kecamatan Sampara tergolong memiliki potensi kemasaman tanah yang cukup tinggi, terlihat dari perbedaan antara $\mathrm{pH}_{F}$ dan $\mathrm{pH}_{\mathrm{Fox}}$ yang cukup besar. $\mathrm{Hal}$ ini juga dapat dilihat dengan dijumpainya tanah di beberapa lokasi yang memiliki reaksi peroksida yang bernilai 2 dan 3. Demikian juga dengan peubah tanah lain $\left(\mathrm{pH}_{\mathrm{KCl}}, \mathrm{pH}_{\mathrm{Ox}}, \mathrm{TPA}, \mathrm{TAA}, \mathrm{TSA}, \mathrm{S}_{\mathrm{TSA}}\right)$ yang menggambarkan kemasaman tanah yang menunjukkan tingkat kemasaman yang relatif tinggi pada tanah di Kecamatan Sampara.

Bahan organik tanah bervariasi dari 1,57\% sampai $19,19 \%$. Konsentrasi bahan organik tanah yang tinggi dijumpai pada lahan yang didominasi oleh tanah gambut, sedangkan konsentrasi bahan organik tanah yang rendah dijumpai pada tanah sulfat masam.

Pada tanah yang dulunya hutan mangrove dengan elevasi agak tinggi terlihat gundukan-gundukan tanah (Gambar 2). Ini merupakan ciri terdapatnya kerongkong (mud lobster, Thalassina anomala) yang merupakan indikator tanah sulfat asam. Pada tanah
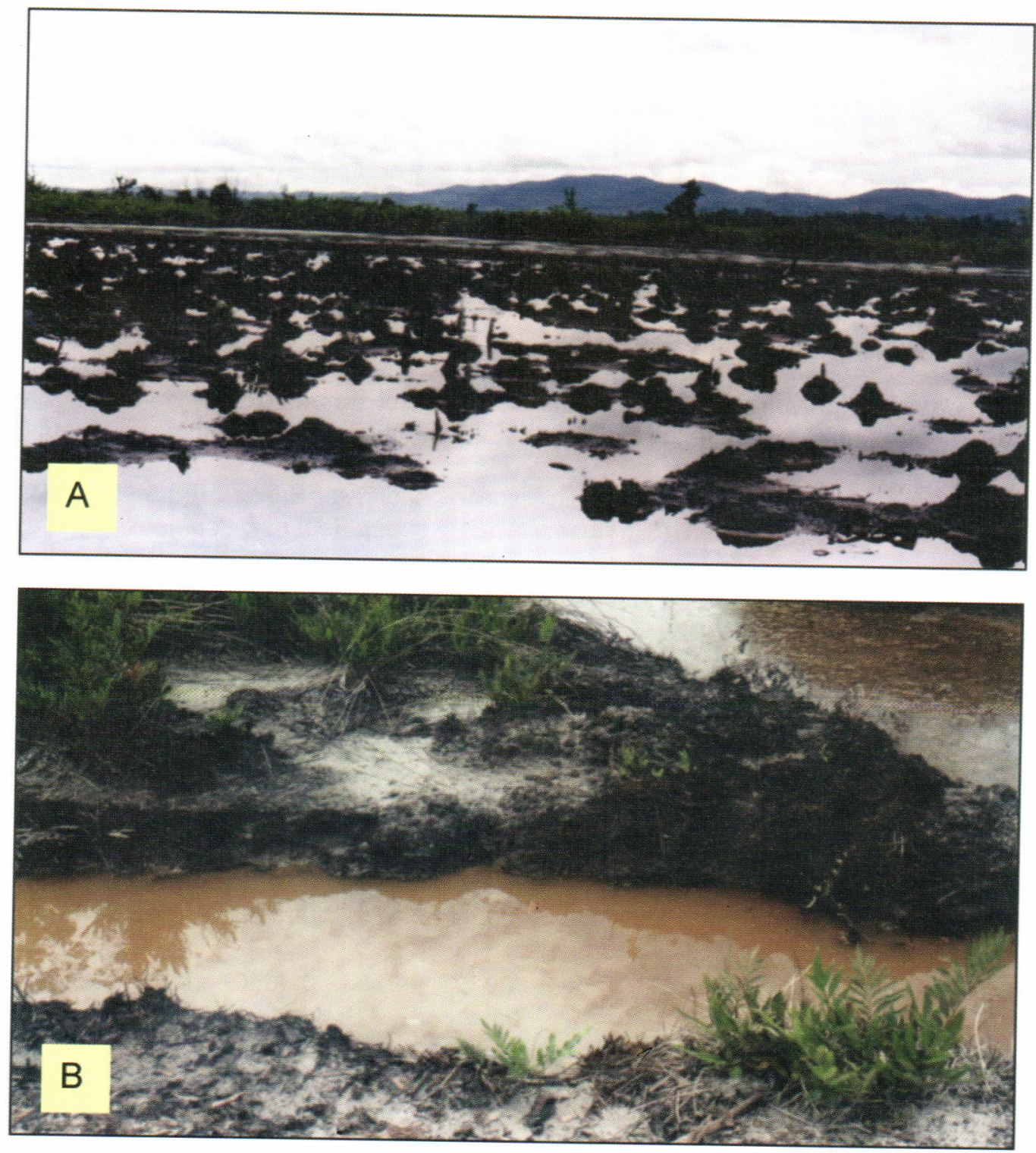

Gambar 2. (A) Gundukan tanah yang dibangun oleh Thalassina anomala merupakan ciri yang baik terdapatnya tanah sulfat masam dan (B) lapisan merah pada permukaan air juga merupakan indikator tanah sulfat masam

Figure 2. (A) Soil mound created by Thalassina anomala is an excellent indicator of Acid Sulfate Soils (B) and red layer on water surface was also a good indicator of acid sulfate soil 
yang telah digali juga dijumpai lapisan warna merah pada permukaan air yang juga menunjukkan tanah yang tergolong tanah sulfat masam.

\section{Kualitas air}

Sumber air laut untuk pertambakan di kawasan pesisir Kecamatan Sampara berasal dari Laut Banda baik melalui saluran maupun sungai, sedangkan sumber air tawar secara umum berasal dari Sungai Sampara. Kualitas air sumber dan tambak di Kecamatan Sampara dapat dilihat pada Tabel 2.

Derajat kemasaman $(\mathrm{pH})$ air di kawasan pesisir Kecamatan Sampara termasuk netral dan sangat mendukung pertumbuhan dan penghidupan organisme budi daya tambak. Salinitas air bervariasi, $30 \mathrm{ppt}$ atau lebih di Laut Banda dan sungai yang tidak memiliki sumber air tawar dan lebih kecil dari 30 ppt di sungai yang memperoleh sumber air tawar. Percampuran air laut dan air payau akhirnya didapatkan salinitas air 20-30 ppt di dalam tambak.

Padatan tersuspensi total yang dapat mempengaruhi kekeruhan dan kecerahan air, ternyata dijumpai dalam konsentrasi yang masih menjamin keberhasilan usaha budi daya tambak. Konsentrasi padatan tersuspensi total yang disarankan oleh Pescod (1973) dalam Wardoyo (1981) adalah tidak melebihi $1.000 \mathrm{mg} / \mathrm{L}$ untuk menjamin keberhasilan usaha budi daya perikanan. Namun demikian, padatan tersuspensi total yang lebih besar dari $1.000 \mathrm{mg} / \mathrm{L}$ dijumpai dalam tambak dan hal ini menuntut adanya pengelolaan fisik air untuk dapat menurunkan padatan tersuspensi total.

Di dalam air, nitrogen dapat hadir dalam bentuk nitrit $\left(\mathrm{NO}_{2}-\mathrm{N}\right)$, nitrat $\left(\mathrm{NO}_{3}-\mathrm{N}\right)$, dan amonia $\left(\mathrm{NH}_{3}-\mathrm{N}\right)$. Nitrit dan amonia merupakan senyawa beracun bagi udang. Namun demikian, konsentrasi bentuk-bentuk nitrogen tersebut di perairan Kecamatan Sampara belum membahayakan penghidupan dan pertumbuhan udang. Poernomo (1992) menyarankan agar konsentrasi $\mathrm{NO}_{2}-\mathrm{N}$ dalam air untuk budi daya tambak tidak melebihi 0,25 mg/L. Pada konsentrasi 0,45 mg/ $\mathrm{L} \mathrm{NH}_{3}-\mathrm{N}$ dapat menghambat laju pertumbuhan udang sampai dengan $50 \%$, sedangkan pada konsentrasi $1,29 \mathrm{mg} / \mathrm{L}$ sudah dapat membunuh beberapa jenis udang penaeid (Wickins, 1976).

Nitrat adalah salah satu bentuk nitrogen yang penting dalam perairan untuk budi daya perairan, karena merupakan bentuk yang dapat dimanfaatkan oleh plankton. Menurut Chu (1943), pertumbuhan optimal plankton berada pada konsentrasi 0,9-3,5 mg/L $\mathrm{NO}_{3} \mathrm{~N}$. Kesuburan perairan untuk budi daya perairan, selain diukur dengan $\mathrm{NO}_{3}-\mathrm{N}$ juga dengan konsentrasi $\mathrm{PO}_{4}-\mathrm{P}$. Konsentrasi $\mathrm{PO}_{4}-\mathrm{P}$ perairan di Kecamatan Sampara tergolong rendah (kurang dari $0,02 \mathrm{mg} / \mathrm{L}$ )

Tabel2. Kualitas air di kawasan pesisir Kecamatan Sampara, Kabupaten Kendari, Provinsi Sulawesi Tenggara Table 2. Water quality in coastal area of Sampara District, Kendari Regency, Southeast Sulawesi Province

\begin{tabular}{|c|c|c|c|c|c|c|c|c|c|}
\hline $\begin{array}{l}\text { Lokasi } \\
\text { Location }\end{array}$ & $\mathrm{pH}$ & $\begin{array}{l}\text { Salinitas } \\
\text { Salinity } \\
\text { (ppt) }\end{array}$ & $\begin{array}{c}\text { PTT } \\
\text { TSS } \\
(\mathrm{mg} / \mathrm{L})\end{array}$ & $\begin{array}{c}\text { BOT } \\
\text { TOM } \\
(\mathrm{mg} / \mathrm{L})\end{array}$ & $\begin{array}{l}\mathrm{NH}_{3}-\mathrm{N} \\
(\mathrm{mg} / \mathrm{L})\end{array}$ & $\begin{array}{l}\mathrm{NO}_{2}-\mathrm{N} \\
(\mathrm{m} \mathrm{g} / \mathrm{L})\end{array}$ & $\begin{array}{l}\mathrm{NO}_{3}-\mathrm{N} \\
(\mathrm{mg} / \mathrm{L})\end{array}$ & $\begin{array}{l}\mathrm{PO}_{4}-\mathrm{P} \\
(\mathrm{mg} / \mathrm{L})\end{array}$ & $\begin{array}{l}\mathrm{SO}_{4}-\mathrm{S} \\
(\mathrm{mg} / \mathrm{L})\end{array}$ \\
\hline $\begin{array}{l}\text { Tambak I } \\
\text { Pond I }\end{array}$ & 7.49 & 25 & 1,172 & 42.08 & 0.1564 & 0.0211 & 0.0425 & 0.0064 & 104.87 \\
\hline $\begin{array}{l}\text { Tambakll } \\
\text { Pond II }\end{array}$ & 7.57 & 29 & 797 & 6.31 & 0.0282 & 0.0062 & 0.0388 & 0.0209 & 97.87 \\
\hline $\begin{array}{l}\text { Sungai Labota } \\
\text { Labota River }\end{array}$ & 7.79 & 5 & 652 & 56.10 & 0.0264 & 0.0062 & 0.0395 & 0.0137 & 90.87 \\
\hline $\begin{array}{l}\text { Sungai Lalimbuejaya } \\
\text { Lalimbuejaya River }\end{array}$ & 7.44 & 30 & 625 & 58.44 & 0.0589 & 0.0039 & 0.0395 & 0.0064 & 109.54 \\
\hline $\begin{array}{l}\text { Sungai Sampara } \\
\text { Sampara River } \\
\text { Sungai Mutui }\end{array}$ & 7.96 & 23 & 505 & 39.74 & 0.0733 & 0.0050 & 0.0388 & 0.0064 & 72.20 \\
\hline $\begin{array}{l}\text { Mutui River } \\
\text { Sungai Pulu }\end{array}$ & 7.34 & 28 & 592 & 6.31 & 0.0246 & 0.0050 & 0.0395 & 0.0064 & 107.21 \\
\hline $\begin{array}{l}\text { Pulu River } \\
\text { Laut Banda }\end{array}$ & 7.93 & 26 & 519 & 56.10 & 0.0860 & 0.0050 & 0.0388 & 0.0064 & 55.87 \\
\hline Banda Sea & 7.52 & 32 & 607 & 65.45 & 0.0752 & 0.0039 & 0.0403 & 0.0064 & 109.54 \\
\hline
\end{tabular}

PTT : padatan tersuspensi total (TSS: total suspended solid)

BOT : bahan organik total (TOM: total organic matter) 
berdasarkan kriteria Joshimaru dalam Liaw (1969). Tampaknya pupuk yang mengandung nitrogen dan fösfor menjadi penting untuk peningkatan produktivitas lahan tambak di Kecamatan Sampara.

\section{Vegetasi dominan}

Telah disebutkan sebelumnya bahwa di lokasi survai dijumpai penggunaan lahan berupa: pemukiman, tambak, kebun campuran, kebun kelapa, dan hutan mangrove. Vegetasi yang dominan dijumpai di setiap jenis penggunaan lahan terlihat pada Tabel 3. Di daerah tambak yang masih bervegetasi pada umumnya dijumpai vegetasi berupa bakau dan nipah. Di daerah pemukiman umumnya dijumpai vegetasi kelapa, jambu mente, dan pisang. Dalam kebun campuran pada umumnya dijumpai vegetasi kelapa, jambu mente, dan beberapa tanaman semak seperti kembang tai ayam.

Vegetasi yang menyusun hutan mangrove di Kecamatan Sampara terdiri atas 11 spesies yang tergolong dalam 10 genus. Dari 10 genus yang ada, ternyata terdapat 3 genus yang termasuk halopitik atau tumbuhan yang menyukai habitat bergaram yaitu: Avicennia sp., Bruguiera sp., dan Rhizophora $\mathrm{sp}$. Kelompok vegetasi tersebut merupakan vegetasi yang menentukan ciri dari hutan mangrove berdasarkan sebaran dan merupakan vegetasi eksklusif yang sangat terikat pada habitat mangrove. Hutan mangrove juga dicirikan dengan adanya vegetasi non-eksklusif yang tidak terikat pada habitat yang ternyata juga dijumpai di areal survai seperti paku laut dan waru laut.

Tabel 3. Vegetasi dominan pada setiap penggunaan lahan di kawasan pesisir Kecamatan Sampara, Kabupaten Kendari, Provinsi Sulawesi Tenggara

Table 3. Predominant vegetation at each land use in coastal area of Sampara District, Kendari Regency, Southeast Sulawesi Province

\begin{tabular}{|c|c|c|}
\hline $\begin{array}{c}\text { Penggunaan lahan } \\
\text { Land use }\end{array}$ & $\begin{array}{l}\text { Nama Indonesia } \\
\text { Indonesian name }\end{array}$ & $\begin{array}{c}\text { Nama ilmiah } \\
\text { Scientific name }\end{array}$ \\
\hline $\begin{array}{l}\text { Tambak } \\
\text { Pond }\end{array}$ & $\begin{array}{l}\text { Bakau hitam } \\
\text { Bakau putih } \\
\text { Nipah }\end{array}$ & $\begin{array}{l}\text { Rhizophora mucronata } \\
\text { Rhizophora apiculata } \\
\text { Nypa fruticans }\end{array}$ \\
\hline $\begin{array}{l}\text { Hutan mangrove } \\
\text { Mangrove forest }\end{array}$ & $\begin{array}{l}\text { Bakau hitam } \\
\text { Bakau putih } \\
\text { Apiapi } \\
\text { Pedada } \\
\text { Tanjang } \\
\text { Waru laut } \\
\text { Nipah } \\
\text { Cemara laut } \\
\text { Pandan } \\
\text { Paku laut } \\
\text { Jeruju }\end{array}$ & $\begin{array}{l}\text { Rhizophora mucronata } \\
\text { Rhizophora apiculata } \\
\text { Avicennia marina } \\
\text { Sonneratia alba } \\
\text { Bruguiera gymnorrhiza } \\
\text { Hibiscus tiliaceus } \\
\text { Nypa fruticans } \\
\text { Casuarina equisetifolia } \\
\text { Pandanus candelabrum } \\
\text { Acrosthicum aureum } \\
\text { Acanthus ilicifolius }\end{array}$ \\
\hline $\begin{array}{l}\text { Kebun campuran } \\
\text { Mix garden }\end{array}$ & $\begin{array}{l}\text { Kelapa } \\
\text { Jambu mente } \\
\text { Pisang } \\
\text { Sagu } \\
\text { Kembang tai ayam }\end{array}$ & $\begin{array}{l}\text { Cocos nucifera } \\
\text { Anacardium occidentale } \\
\text { Musa sapientum } \\
\text { Metroxylon sago } \\
\text { Tagetes erecta }\end{array}$ \\
\hline $\begin{array}{l}\text { Kebun kelapa } \\
\text { Coconut garden }\end{array}$ & Kelapa & Cocos nucifera \\
\hline $\begin{array}{l}\text { Pemukiman } \\
\text { Settlement }\end{array}$ & $\begin{array}{l}\text { Beluntas } \\
\text { Kelapa } \\
\text { Pisang } \\
\text { Jambu mente } \\
\text { Ubi kayu } \\
\text { Ubi jalar }\end{array}$ & $\begin{array}{l}\text { Pluchea indica } \\
\text { Cocos nucifera } \\
\text { Musa sapientum } \\
\text { Anacardium occidentale } \\
\text { Manihot esculents } \\
\text { Ipomoea batatas }\end{array}$ \\
\hline
\end{tabular}


Tiap spesies vegetasi mangrove mempunyai habitat tersendiri atau membentuk zonasi tersendiri menurut tuntutannya terhadap siklus hidupnya. Faktor utama yang menyebabkan adanya zonasi di hutan mangrove adalah sifat-sifat tanah, di samping faktor salinitas, frekuensi, dan kategori penggenangan air dan ketahanan suatu spesies terhadap ombak dan arus.

Paku laut umumnya dijumpai dalam hutan mangrove yang telah ditebang dan selanjutnya ditelantarkan. Nipah tidak hanya dijumpai di pinggir sungai yang memiliki sumber air tawar seperti di Sungai Sampara dan Labota, tetapi juga dijumpai di daerah pantai yang masih mendapat suplai air tawai. Di daerah yang bersalinitas tinggi seperti di muara Sungai Lalimbuejaya dan Mutui, vegetasi mangrove didominasi oleh Rhizophorasp.

Pengaruh sifat tanah terhadap mangrove antara lain ditunjukkan oleh sebaran Rhizophora sp. Di daerah dengan tanah berlumpur dalam, $R$. mucronata merupakan vegetasi yang dominan (Chapman, 1976) dan di daerah dengan lumpur dangkal didominasi oleh R. apiculata (Hardjowigeno, 1987). Di Kecamatan Sampara, Rhizophora sp. yang merupakan vegetasi dominan dalam hutan mangrove dijumpai pada tanah dengan tekstur lempung liat berdebu, liat berpasir, dan lempung liat berpasir. Cemara laut dijumpai di pantai berpasir muara Sungai Mutui.

\section{Kelayakan Iahan}

Dengan berdasarkan berbagai pertimbangan, maka ditetapkan beberapa peubah kualitas tanah seperti disajikan pada Tabel 2 dan yang menjadi kunci keberhasilan usaha budi daya tambak (terutama di tambak tanah sulfat masam) dan relatif bersifat permanen yang akan menjadi data base dalam analisis SIG.

Selain data base, dalam analisis SIG juga diperlukan peta peruntukan lahan yang akan digunakan dalam analisis spasial dan koreksi geografis data base. Seperti dikatakan sebelumnya bahwa di Kecamatan Sampara didapatkan 5 jenis peruntukan lahan yaitu tambak, kebun campuran, hutan mangrove, kebun kelapa, dan pemukiman dengan luas berturut-turut 510,10 ha (tambak lama 394,37 ha dan tambak baru 115,73 ha); 323,97 ha; 264,41 ha; 7,58 ha; dan 100,57 ha (Gambar 3) yang sekaligus menggambarkan kondisi land unit.

Berdasarkan hasil survai tambak sebelumnya terutama tambak tanah marginal seperti tanah sulfat masam dan tanah gambut serta referensi yang ada,

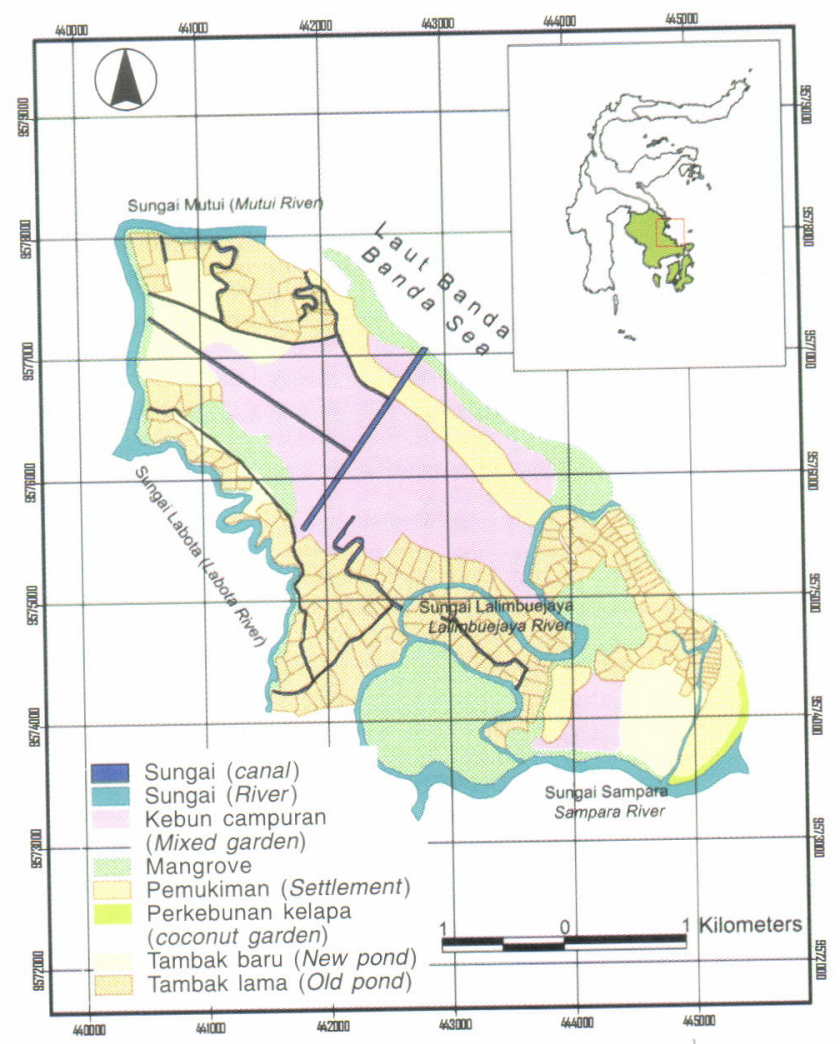

Gambar 3. Peta penggunaan lahan di kawasan pesisir Kecamatan Sampara, Kabupaten Kendari, Provinsi Sulawesi Tenggara

Figure 3. Map of land use in coastal area of Sampara District, Kendari Regency, Southeast Sulawesi Province 
maka ditetapkan kriteria kelayakan lahan yang ada seperti terlihat pada Tabel 4.

Berdasarkan kriteria kelayakan tersebut, yang menggunakan analisis grafis dengan metode tumpang tindih didapatkan berbagai peta tematik untuk setiap peubah kelayakan (Gambar 3). Tumpang tindih dari berbagai peta tematik yang masih bersifat individu tersebut akhirnya diperoleh peta yang sudah merupakan integrasi dari beberapa peubah dengan tiga kode kelayakan yaitu: kelayakan tinggi, kelayakan sedang, dan kelayakan rendah (Gambar 4).

Dari Gambar 4 terlihat bahwa sekitar 483,77 ha $(40,1 \%)$ kawasan pesisir Kecamatan Sampara tergolong kelayakan tinggi: 592,55 ha $(49,1 \%)$ tergolong kelayakan sedang dan 130,32 ha $(10,8 \%)$ tergolong kelayakan rendah untuk budi daya tambak.
Lokasi yang tergolong kelayakan tinggi secara umum berada dalam area yang tergolong lahan supratidal yang juga secara umum mempunyai keunggulan kualitas tanah dibandingkan dengan lahan intertidal di mana area yang tergolong kelayakan sedang dan kelayakan rendah berada. Pada daerah yang tergolong kelayakan tinggi $\mathrm{pH}$ tanah umumnya sekitar netral dan merupakan kondisi yang baik untuk pertumbuhan makanan alami maupun organsime akuatik di tambak. Selain itu, tekstur tanah yang tergolong lempung liat berpasir sampai lempung liat berdebu, sangat baik untuk tambak karena tidak porous atau dapat menahan air dalam jangka waktu yang lama.

Lokasi yang tergolong kelayakan sedang umumnya berada di daerah intertidal. Dalam peta penggunaan lahan (Gambar 3) umumnya sekarang

Tabel 4. Kriteria kelayakan setiap peubah tanah untuk budi daya tambak

Table 4. Suitability criteria of each soil variable for brackishwater pond

\begin{tabular}{|c|c|c|c|}
\hline \multirow{2}{*}{$\begin{array}{l}\text { Peubah } \\
\text { Variables }\end{array}$} & \multicolumn{3}{|c|}{$\begin{array}{c}\text { Tingkat kesesuaian } \\
\text { Rate of suitability } \\
\end{array}$} \\
\hline & $\begin{array}{c}\text { Tinggi } \\
\text { High }\end{array}$ & $\begin{array}{l}\text { Sedang } \\
\text { Moderat }\end{array}$ & $\begin{array}{l}\text { Rendah } \\
\text { Low }\end{array}$ \\
\hline \multirow[t]{2}{*}{$\mathrm{pH}_{\mathrm{F}}$} & $6.5--7.5$ & $4.5--6.5$ & $<4.5$ \\
\hline & & $7.5--8.0$ & $>8.0$ \\
\hline \multirow[t]{2}{*}{$\mathrm{pH}_{\text {Fox }}$} & $6.0--7.0$ & $4.0--6.0$ & $<4.0$ \\
\hline & & $7.0-8.0$ & $>8.0$ \\
\hline $\begin{array}{l}\text { Bahan organik } \\
\text { Organic matter }(\%)\end{array}$ & $<10$ & $10--20$ & $>20$ \\
\hline \multirow[t]{2}{*}{$\mathrm{pH} \mathrm{KCl}_{\mathrm{L}}$} & $6.0--8.0$ & $5.0-6.0$ & $<5.0$ \\
\hline & & 8.0--9.0 & $>9.0$ \\
\hline \multirow[t]{2}{*}{$\mathrm{pH}_{\mathrm{Ox}}$} & $4.0--5.0$ & $3.0--4.0$ & $<3.0$ \\
\hline & & $5.0-6.0$ & $>6.0$ \\
\hline TPA $\left(\mathrm{mol} \mathrm{H}^{+} / \mathrm{t}\right)$ & $<200$ & $200--600$ & $>600$ \\
\hline TAA $\left(\mathrm{mol} \mathrm{H}^{+} / \mathrm{t}\right)$ & $<5$ & $5-40$ & $>40$ \\
\hline TSA $\left(\mathrm{mol} \mathrm{H}^{+} / \mathrm{t}\right)$ & $<100$ & $100--500$ & $>500$ \\
\hline $\mathrm{S}_{\mathrm{TSA}}(\%)$ & $0--0.5$ & $0.5--1.0$ & $>1.0$ \\
\hline Tekstur (Texture) & $\begin{array}{c}\text { Lempung liat berpasir (Sandy } \\
\text { clay loam), Lempung berliat } \\
\text { (Clay loam), Lempung liat } \\
\text { berdebu (Silty clay loam) }\end{array}$ & $\begin{array}{c}\text { Lempung (Loam), Lempung } \\
\text { berdebu (Silty loam), Liat } \\
\text { berdebu (Silty clay), Liat } \\
\text { berpasir (Sandy clay) }\end{array}$ & $\begin{array}{l}\text { Pasir (Sand), } \\
\text { Liat (Clay), } \\
\text { Debu (Silt) }\end{array}$ \\
\hline $\begin{array}{l}\text { TPA }: \text { Total potentia } \\
\text { TAA : Total actual a } \\
\text { TSA : Total sulfidic } \\
\text { STSA : TSA calculate }\end{array}$ & $\begin{array}{l}\text { acidity } \\
\text { cidity } \\
\text { cidity } \\
\text { d as equivalent pyrit S\% }\end{array}$ & & \\
\hline
\end{tabular}



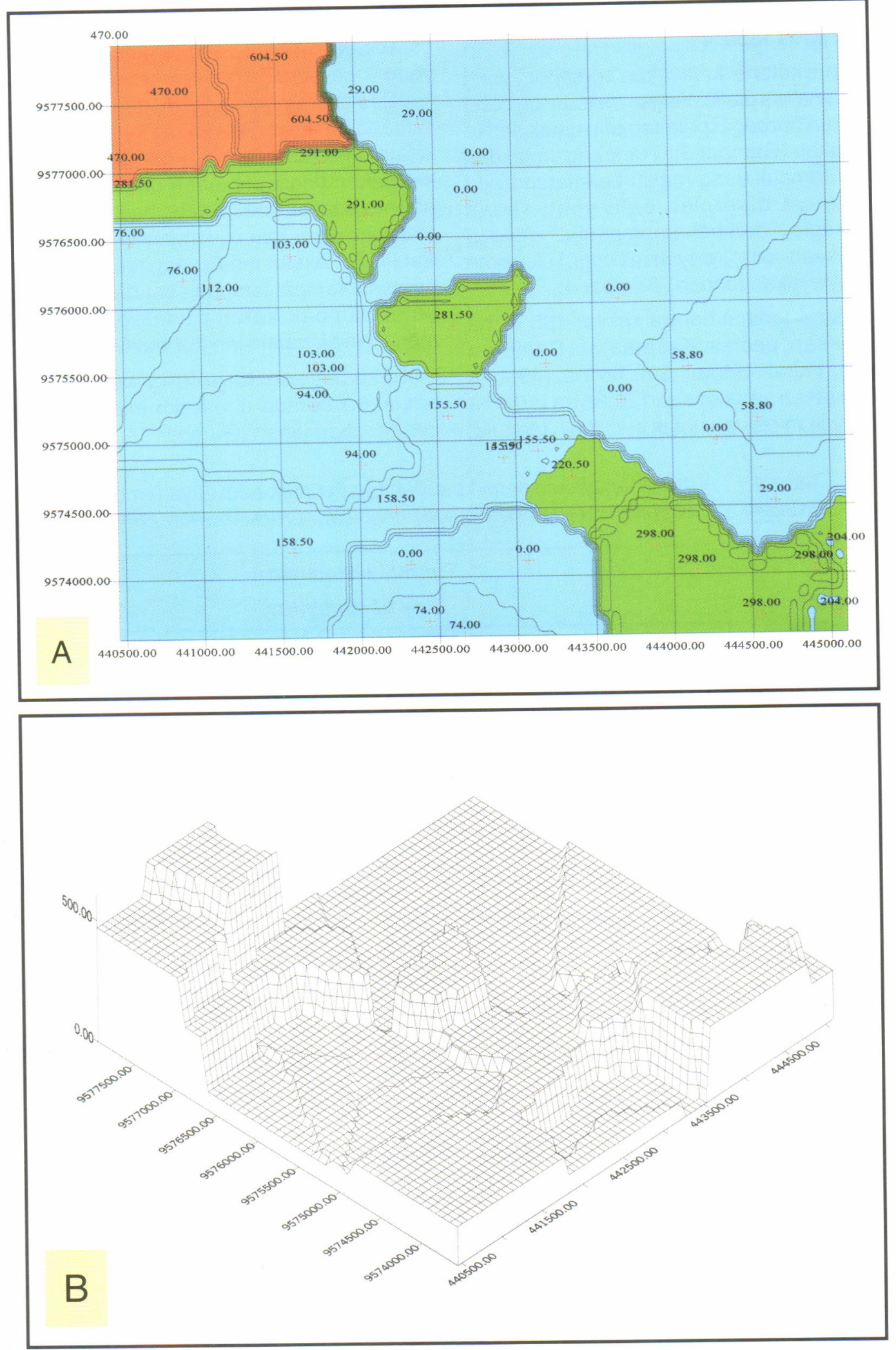

Gambar 4. Peta tematik total potential acidity (TPA) tanah di kawasan pesisir Kecamatan Sampara, Kabupaten Kendari, Provinsi Sulawesi Tenggara (A: Distribusi TPA; B: Penampakan tiga dimensi TPA)

Figure 4. Thematic map of total potential acidity (TPA) of soil in coastal area of Sampara District, Kendari Regency, Southeast Sulawesi Province (A: Distribution of TPA; B: Three dimension performance of TPA) 
ini digunakan untuk tambak yang berasal dari hutan mangrove dengan jenis tanah secara umum tergolong tanah sulfat masam. Tanah yang agak masam dan tekstur tanah lempung sampai liat berpasir adalah kondisi tanah di daerah ini.

Lokasi dengan kelayakan rendah juga dijumpai di kawasan intertidal. Tanah yang dominan di daerah ini tergolong tanah gambut dan tanah sulfat masam yang berasosiasi dengan tanah gambut dengan konsentrasi bahan organik yang sangat tinggi. Derajat kemasaman tanahnya tergolong sangat masam sampai agak masam. Kondisi fisik tanah gambut kurang menguntungkan untuk tambak mengingat tanahnya sangat porous dan kecepatan penurunan permukaan tanah yang cukup tinggi. Tanah gambut daya rembes air secara vertikal sangat lambat, sedangkan secara horizontal sangat cepat. Juga telah dilaporkan bahwa penurunan permukaan tanah dari pematang tambak tanah gambut dapat mencapai $12-19 \mathrm{~cm}$ selama 4 bulan (Mustafa et al., 1995).

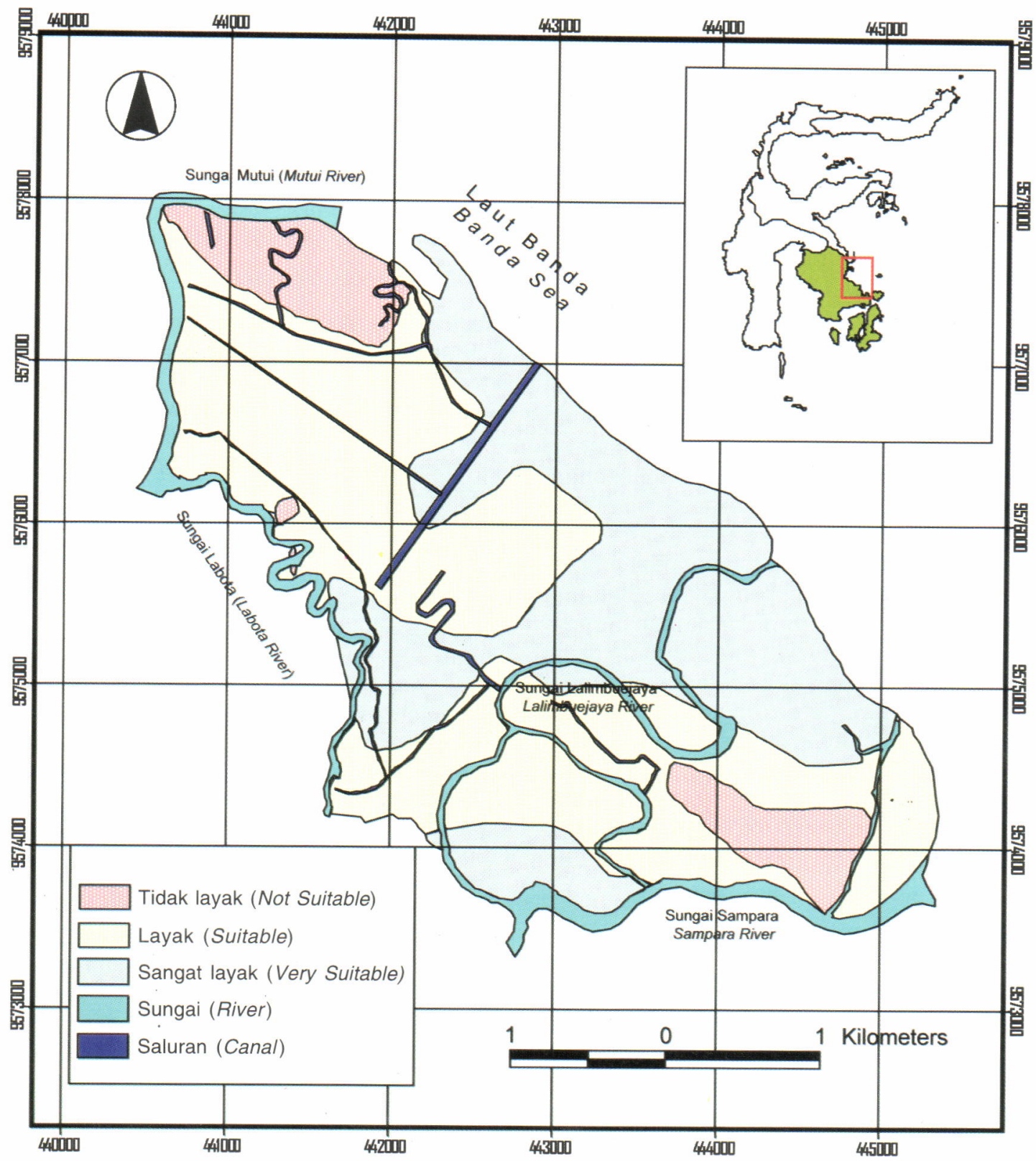

Gambar 5. Peta kelayakan lahan untuk budi daya tambak di kawasan pesisir Kecamatan Sampara, Kabupaten Kendari, Provinsi Sulawesi Tenggara

Figure 5. Map of land suitability for brackishwater pond in coastal area of Sampara District, Kendari Regency, Southeast Sulawesi Province 
Tanah sulfat masam merupakan tanah yang dominan di kawasan pesisir Kecamatan Sampara yang mengandung pirit yang menyebabkan $\mathrm{pH}$ tanah rendah. Untuk menurunkan kemasaman atau meningkatkan $\mathrm{pH}$ tanah sulfat masam yang sekaligus menurunkan senyawa penyebab kemasaman tanah, maka dapat dilakukan perbaikan tanah atau reklamasi dengan jalan penjemuran, perendaman, dan pencucian tanah. Dengan penjemuran terjadi pemecahan senyawa pirit yang tidak larut menjadi larut dalam air. Senyawa yang larut dalam air rendaman akhirnya ikut terbuang pada saat pencucian. Selain dengan proses reklamasi, pengapuran ternyata juga dapat membantu meningkatkan $\mathrm{pH}$ tanah, mengurangi senyawa penyebab kemasaman tanah, dan meningkatkan daya sangga tanah serta meningkatkan ketersediaan unsur yang bersifat basa maupun unsur hara lain. Strategi manajemen air dapat digunakan untuk membatasi oksidasi pirit, pergerakan produksi oksidasi, netralisasi dan pengenceran asam, dan penurunan aluminium dan besi (Sammut, 1999).

Dalam kelayakan lahan ini belum dipertimbangkan aspek jalur hijau dalam penentuan kelayakan lahan. Namun demikian, berdasarkan pasal 27 Keppres RI No. 32 Tahun 1990 tentang Pengelolaan Kawasan Lindung dan data rata-rata tunggang air pasang purnama di sekitar lokasi survai (Bird \& Ongkosongo, 1980 dalam Soerianegara, 1989), maka lebar jalur hijau di pinggir pantai Kecamatan Sampara adalah $130 \mathrm{~m}$. Lebar jalur hijau di tepi sungai (sempadan sungai) yang diatur pada pasal 16 Keppres RI No. 32 tahun 1999 adalah minimal 100 m di kiri kanan Sungai Sampara dan Sungai Mutui dan minimal $50 \mathrm{~m}$ di kiri kanan Sungai Lalimbuejaya, Labota, dan Sungai Pulu. Manfaat jalur hijau hutan mangrove di daerah pertambakan adalah untuk melestarikan sumber daya pertambakan, melindungi pertambakan dari hempasan ombak atau gerusan aliran sungai, melindungi tempat pemukiman dari hembusan angin laut, serta melestarikan ekosistem pantai dan mangrove.

\section{KESIMPULAN}

1. Tanah sulfat masam merupakan salah satu jenis tanah yang dijumpai di kawasan pesisir Kecamatan Sampara, Kabupaten Kendari, Provinsi Sulawesi Tenggara dan berada di kawasan yang sumber airnya cukup mendukung untuk usaha budi daya tambak. Karakteristik tanah sulfat masam ditandai dengan $\mathrm{pH}$ rendah dan potensi kemasaman tanah tinggi. Vegetasi yang dominan sangat tergantung pada kondisi habitatnya masing-masing.

2.Berdasarkan kriteria kelayakan tanah untuk budi daya tambak, maka di kawasan pesisir Kecamatan
Sampara, Kabupaten Kendari, Provinsi Sulawesi Tenggara didapatkan lahan seluas 483,77 ha termasuk kelayakan tinggi; 592,55 ha termasuk kelayakan sedang; dan 130,32 ha termasuk kelayakan rendah atau tidak layak untuk budi daya tambak.

\section{DAFTAR PUSTAKA}

Ahern, C.R., A. McElnea, and D.E. Baker. 1998. Peroxide oxidation combined acidity \& sulphate: Pocas-Method 21. In Stone, Y., Ahern, C.R., and Blunden, B. (Eds.). Acid Sulfate Soils Manual. Acid Sulfate Soil Management Advisory Committee, Wollongbar, NSW, Australia, p. 4.1-4.17.

Ahern, C.R. and B. Blunden. 1998. Designing a soil sampling and analysis program. In Stone, Y., Ahern, C.R., and Blunden, B. (Eds.). Acid Sulfate Soils Manual. Acid Sulfate Soil Management Advisory Committee, Wollongbar, NSW, Australia, p. 2.1-2.5.

APHA (American Public Health Association). 1998. Standard Methods for Examination of Water and Wastewater. $20^{\text {th }}$ edition. APHA, AWWA, WEF, Washington, $1,085 \mathrm{pp}$.

Chapman, V.J. 1976. Mangrove Vegetation. Strauss and Cramer $\mathrm{GmbH}$, Leutershausen, Germany, 447 pp.

Chu, S.P. 1943. The influence of the mineral composition of the medium on the growth of planktonic algae. Part II. The influence of concentration of inorganic nitrogen and phosphate phosphorus. Journal Ecology, 31(2): 109-148.

Gonzales, E.V., A.E. Manas, E.I. Mule, J.R. Filamor, C.C. Maza, and R. Marero. 1974. Tannin extract production from local materials. FORPRIDED Digest, $3(3,4): 10-22$.

Hardjowigeno, S. 1987. Status pengetahuan tanahtanah mangrove di Indonesia. Dalam Soerianegara, I., Adisoemarto, S., Soemadihardjo, S., Hardjowigeno, S., Sudomo, M., dan Ongkosongo, O.S.R. (Eds.). Prosiding Seminar III Ekosistem Mangrove. Panitia Program MAB Indonesia-LIPI, Jakarta, p. $156-163$.

Liaw, W.K. 1969. Chemical and biological studies of fish ponds and reservoirs in Taiwan. Reprinted from Chinese-American Joint Commission on Rural Reconstruction. Fish Series, (7):1-43.

Menon, R.G. 1973. Soil and Water Analysis: A Laboratory Manual for the Analysis of Soil and Water. Proyek Survey O.K.T. Sumatera Selatan, Palembang, 190 pp.

Mustafa, A. dan A. Hanafi. 1996. Pola penataan kawasan tambak berwawasan lingkungan. Disajikan pada Rapat Kerja Teknis Balai Penelitian Perikanan Pantai, Makassar Golden Hotel Ujung Pandang, 17-18 April 1996. Balai Penelitian Perikanan Pantai, Maros, 19 pp.

Mustafa, A., A. Hanafi, dan B. Pantjara. 1995. Konstruksi pematang tambak tanah gambut untuk pendederan benih udang windu (Penaeus monodon) dan nener ikan bandeng (Chanos chanos). J. Pen. Per. Indonesia. I (2): 48-64. 
Mustafa, A., A. Hanafi, B. Pantjara, dan Suwardi. 1994. Karakteristik lahan mangrove di Delta Tampinna, Kabupaten Luwu, Sulawesi Selatan. Dalam Mansur, H., Rachmansyah, Atmomarsono, M., dan Mustafa, A. (Eds.). Risalah Seminar Hasil Penelitian Perikanan Budidaya Pantai. Balai Penelitian Perikanan Budidaya Pantai, Maros, p. 95-105.

Notohadiprawiro, T. 1986. Tanah Estuarin: Watak, Sifat, Kelakuan dan Kesuburannya. Ghalia Indonesia, Jakarta, 142 pp.

Nurjana, M.L. 1999. Kebijakan pengembangan perikanan budidaya pesisir mendukung gema PROTEKAN 2003. Disajikan pada Rapat Kerja Teknis Balai Penelitian Perikanan Pantai, Wisma Kinasih Gemilang Bogor, 16-17 Maret 1999. Direktorat Jenderal Perikanan, Jakarta, 18 pp.

Poernomo, A. 1992. Pemilihan Lokasi Tambak Udang Berwawasan Lingkungan. Badan Penelitian dan Pengembangan Pertanian, Jakarta, 40 pp.

Purwadhi, F.S.H. 1999. Sistem Informasi Geografis. Dalam Suhermanto, Tjinda, F., Yulimantoro, S., Arisdyo, I.L., Ginting, R., dan Effendi, A. (Eds.). Pengantar
Teknologi, Aplikasi Penginderaan Jauh Satelit dan Sistem Informasi Geografi. Lembaga Penerbangan dan Antariksa Nasional dan Badan Pengkajian dan Penerapan Teknologi, Jakarta, p. 367-494.

Sammut, J. 1999. Amelioration and management of shrimp ponds in acid sulfate soils: Key researchable issues. In Smith, P.T. (Ed.). Towards Sustainable Shrimp Culture in Thailand and the Region. Australian Centre for International Agricultural Research, Canberra, p. 102-106.

Soerianegara, I. 1989. Manfaat jalur hijau hutan man. grove di daerah pertambakan dan cara penentuannya. Dalam KEPAS, Pengembangan Budidaya Tambak di Indonesia: Masalah dan Alternatif. Badan Penelitian dan Pengembangan Pertanian, Jakarta, p. 37-45.

Wardoyo, S.T.H. 1981. Kriteria kualitas air untuk keperluan perikanan. Training Analisa Dampak Lingkungan Kerja Sama PPLH, UNDIP-PLH, dan IPB. Institut Pertanian Bogor, Bogor.

Wickins, J.F. 1976. The tolerance of warm-water prawns to recirculated water. Aquaculture, 9: 19-37. 
